Investigaciones Fenomenológicas, n. 9, 2012, 117-143.

e-ISSN: $1885-1088$

\title{
LA CONSTITUCIÓN DEL SUJETO DE LA EXPERIENCIA AFECTIVA. Descartes. Nietzsche. Heidegger
}

\author{
Irene Breuer \\ ibreuer@hotmail.com
}

\begin{abstract}
Resumen: La tesis principal sostiene que Descartes, mucho antes que Nietzsche, sentó las bases para la aserción de la fenomenalidad del mundo interno, el cual posee los atributos de certeza e indubitalidad de las que carecen los fenómenos externos de la percepción. Después de un primer analisis del alcance del cógito de las Meditaciones, de la crítica al mismo de Nietzsche y finalmente de la crítica de Heidegger a ambos, se analizan los problemas inherentes a sus respectivos planteos. Mientras que el cógito de las Meditaciones sólo prueba la existencia del ser sustancial inmaterial, el Tratado de las pasiones y ciertas cartas de Descartes permiten la postulación de un "yo" sustrato del compuesto alma-cuerpo que no sólo es sede de las pasiones y acciones, sino que alberga emociones ciertas e indudables que permiten la constitutición de un sujeto de la experiencia afectiva. El análisis de la subjetividad en Nietzsche revelará que, aunque el sujeto es sólo una ficción útil, comparte ciertos rasgos con la subjetividad afectiva postulada: las emociones remiten al mundo exterior en cuanto éste es sentido $y$, en cuanto le advienen al alma y la afectan irremisiblemente, no pueden ser puestas en duda.
\end{abstract}

Palabras clave: Subjetividad, experiencia afectiva, emociones, certeza, Descartes, Nietzsche, Heidegger.

\begin{abstract}
The main thesis claims that Descartes, long before Nietzsche, supplied the theoretical foundations to state the phenomenality of the internal world, which possesses the attributes of certainty and unquestionability the phenomena of external perception lack. After analyzing the range of and Nietzsche's critique to the cogito at the Meditations and Heidegger's critique to both authors, the resulting critical points inherent to their respective conceptions are disclosed. While the cogito of the Meditations only proves the existence of the immaterial substance, I endeavor to show that the Passions of the soul and a selection of his correspondence allow the assumption of an "I" substrate of the soul-mind union, which is the seat not only of passions and actions, but of certain and undoubtful emotions that allow for the constitution of a subject of affective experience. A close examination of Nietzsche's understanding of subjectivity will finally reveal that, although the subject is only a useful fiction, it shares some fundamental traits with the affective subjectivity posed here: emotions refer to the external world as sensed, and inasmuch as they befall and irrevocably affect the soul cannot be subjected to doubt.
\end{abstract}

Keywords: Sujbectivity, affective experience, emotions, certainty, Descartes, Nietzsche, Heidegger.

INTRODUCCIÓN ${ }^{1}$

A partir del alcance del cógito cartesiano en las Meditaciones y del planteo de un "yo" sustrato en el Tratado de las pasiones, el escrito plantea como tesis

\footnotetext{
${ }^{1}$ Este trabajo es una versión modificada de uno de los capítulos de mi tesis de Licenciatura en Filosofía intitulada: "La diferencia y el umbral de la Metafísica", presentada en la Facultad de Filosofía y Letras de la Universidad de Buenos Aires en el año 2003 y escrita bajo la dirección de la Dra. Mónica Cragnolini, a quien agradezco no sólo su dedicación sino el haber despertado mi interés en Nietzsche.
} 
principal que Descartes, antes que Nietzsche, postuló la fenomenalidad del mundo interno, el cual posee las notas de certeza e indubitabilidad de las que carecen los fenómenos externos de la percepción. Mientras que el cogito de las Meditaciones sólo prueba la existencia del ser sustancial inmaterial, el Tratado de las pasiones permite la asunción de un "yo" sustrato del compuesto almacuerpo en tanto es sede de las pasiones y de las acciones y en cuanto alberga emociones que son "ciertas" e indudables. Este yo sustrato del compuesto no sólo hereda la certeza que en las Meditaciones estaba reservada al cogito, sino que se constituye en un yo de la experiencia, un yo empírico y variable. El análisis de la subjetividad en Nietzsche revelará que el "sujeto" no es un sustrato, sino un sujeto "disgregado" en multitud de pasiones, heterogéneas y no unificables. A pesar de que el sujeto no es sino una ficción útil, el caos informulable de las emociones que lo atraviezan constituye el único mundo que podemos reconocer: Los afectos no sólo forman el lazo de unión entre nuestros pensamientos, sino que además, los guían; sólo ellos son irrefutablemente sentidos, aun cuando no se pueda afirmar su verdad. Por ende, ambas concepciones comparten un elemento común: las emociones nos permiten un acceso al mundo exterior en cuanto sentido, y dado que ellas sobrevienen al alma y la afectan irremisiblemente, no pueden ser puestas en duda.

El trabajo se estructura de la siguiente manera: Después de una introducción a la noción de substancia en la Modernidad se realiza un primer análisis del alcance del cogito cartesiano en las Meditaciones y se señalan los problemas inherentes a su planteo. En un segundo paso se analizan las críticas de Heidegger a Descartes y a Nietzsche en lo que atañe a sus respectivas concepciones de la subjetividad y se revelan los presupuestos de los que parte Heidegger. A continuación se discute y se profundiza la crítica de Nietzsche al ego cartesiano para poder así plantear la tesis principal del trabajo: la fenomenalidad del mundo interno y la certeza de las emociones en Descartes. Finalmente se desarrolla el tema de la subjetividad en Nietzsche y su relación con la concepción de la totalidad del mundo que, en tanto inabordable e indecidible, plantea un límite al pensamiento metafísico moderno. 


\section{LA RACIONALIDAD Y LA NOCIÓN DE "SUBSTANCIA" EN LA MODERNIDAD}

La racionalidad como adecuación del alma al orden de un mundo independiente y ordenado de ideas, propia del planteo platónico, es entendida en la Modernidad como la capacidad de construir órdenes que se basen en criterios de certeza y evidencia, conformes a una actividad del pensar, más que a una determinada realidad ${ }^{2}$. En lugar de considerar la naturaleza como efectivización del mundo de las ideas, Descartes distingue entre el mundo material, mera extensión, y el mundo espiritual, el del pensamiento. La distinción ontológica entre espíritu y extensión se complementa con su unión, la del compuesto almacuerpo, sede de las acciones y las pasiones.

La noción de substancia ${ }^{3}$ implica, en la Modernidad, el ser causa de sí misma, lo que supone que una substancia no deberá depender causalmente de ninguna otra cosa para existir. Substancia propiamente dicha será aquello que es causa sui, lo que conlleva que todos los cambios que pueda sufrir ocurren independientemente de que existan o no otras sustancias. Si todas las sustancias se causan a sí mismas, su interacción resta por explicar, lo que implica el problema de la causalidad, pues se debe dar cuenta de la posibilidad de la adecuación entre ideas y mundo y -con él relacionado- la cuestión de la objetividad, pues se debe justificar cómo las impresiones o apariencias que percibimos se adecuan al mundo. Se plantean entonces dos problemas: el primero, la validez objetiva de nuestras ideas, y el segundo, la verdad y justificación del conocimiento, para lo cual es necesaria la garantía divina. En la Modernidad, los filósofos se preguntan por la unidad detrás de la multiplicidad de las apariencias (validez objetiva) y por la naturaleza esencial de una substancia (validez cognoscitiva). Basados en el modelo de la ciencia matemática, conocer implica catalogar las diferencias cualitativas y cuantitativas esenciales, establecer sus atributos esenciales es pues, un calcular. La racionalidad se basa en el operar matemático.

\footnotetext{
${ }^{2}$ Leiser Madanes, El optimismo racionalista del siglo XVII, Buenos Aires, Secretaría de Publicaciones del Centro de Estudiantes de la Facultad de Filosofía y Letras / UBA, sin indicación de año, p. 3.

${ }^{3}$ Para un análisis de la los problemas que implican la noción de substancia en los siglos XVII y XVIII ver Leiser Madanes, La noción de substancia y sus problemas, Buenos Aires, Secretaría de Publicaciones del Centro de Estudiantes de la Facultad de Filosofía y Letras / UBA, sin indicación de año.
} 


\section{EL COGITO CARTESIANO ${ }^{4}$}

La razón en Descartes es una facultad intuitivo-deductiva. En la deducción, que tiene carácter temporal, el error es posible, mientras que en la intuición se capta la verdad y no hay error ni tiempo. El cogito como se plantea en la Segunda Meditación es, a primera vista, una intuición racional: "yo soy, yo existo, es necesariamente verdadero siempre que la pronuncio o concibo en mi espíritu". En una segunda formulación no intuitiva ${ }^{5}$, se introduce el tiempo como instantaneidad: "engáñeme cuanto quiera, que nunca podrá hacer que yo sea nada mientras piense ser algo"6; y agrega, "yo soy el que piensa, entiende, desea", es decir, una cosa que afirma, niega, desea, etc. ${ }^{7}$. Dos problemas se presentan en el establecimiento del "yo": a) el razonamiento deriva de la existencia del pensamiento a la existencia del sujeto pensante b) el cogito es un "yo" ahistórico, que subyace a sus operaciones, como destaca Ricoeur ${ }^{8}$, y escapa a la alternativa de permanencia y cambio en el tiempo porque es instantáneo, es un acto.

En este sentido, se trata sólo de alcanzar el ser en la medida en que pensamos, yo soy y existo todo el tiempo que dure mi pensar. Como indica Hame$\operatorname{lin}^{9}$, no se trata de establecer la totalidad del ser, pues el ser que Descartes establece "es sólo el ser de nuestro pensamiento". Más adelante, sin embargo, los hábitos realistas hacen que el ser del pensamiento sea concebido conforme al tipo de sustancia y de la cosa; el pienso (instantáneo) y el ser pensante significan lo mismo, ya que según Descartes "no podemos concebir ningún acto sin sujeto" ${ }^{10}$. El acto de pensar se asimila al pensamiento y éste al ser de la sustancia y ésta a su vez, a la materia ("soy una cosa que piensa"). "Descartes

\footnotetext{
${ }^{4}$ Mi agradecimiento al Prof. Dr. Roberto Walton, cuyos seminarios en la cátedra de "Gnoseología" por él dirigida- no sólo despertaron mi interés en Husserl y Heidegger, sino que -junto con la Prof. Beatriz Von Bilderling y el Prof. Leiser Madanes de la cátedra de "Filosofía Moderna"- sentaron las bases de mi comprensión de la subjetividad en la Modernidad.

${ }^{5}$ Como aclara Descartes, la deducción puede implicar un movimiento del espíritu, o el término de un movimiento, cuando la deducción ha sido realizada, pues "se la ve como intuición porque es simple y clara". René Descartes, Obras escogidas, Buenos Aires, Sudamericana, 1967, pp. 77s. Trad. de Ezequiel Olaso y Tomás Zwanck.

${ }^{6}$ René Descartes, Meditaciones metafísicas, Segunda Meditación, en Obras escogidas, p. 224.

${ }^{7}$ René Descartes, Meditaciones metafísicas, p. 277.

8 Paul Ricœur, Oneself as Another, Chicago, The University of Chicago Press, 1992, p. 7. Trad. Kathleen Blamey.

${ }^{9}$ Octave Hamelin, El Sistema de Descartes, Buenos Aires, Losada, 1949, p. 92. Trad. Amalia Haydée Raggio.

${ }^{10}$ René Descartes, Meditaciones metafísicas con objeciones y respuestas, Barcelona, Alfaguara, 1977. Trad. de Vidal Peña.
} 
creyó que 'ser' era sinónimo de 'ser sustancial'", por lo que cosificó al pensamiento, otorgándole existencia a su soporte. Descartes plantea así un yo trascendente, pues este cogito trasciende a la realidad: "del hecho de ser pensante se infiere que soy, porque lo que piensa es algo"11. Hamelin señala que Descartes excedió el "alcance del cogito": el cogito no constituye la ratio essendi del ser pensante, sino únicamente su ratio cognoscendi ${ }^{12}$, el pensamiento implica un sujeto pensante y porque veo eso en mí, veo que existo ${ }^{13}$. El cogito entonces no plantea la esencia del yo pensante sino sólo la posibilidad de reconocer la existencia. Lo que se prueba es, pues sólo la existencia del ser sustancial inmaterial, la sustancia pensante, no implicando necesariamente un "soporte" material.

\section{LA INTERPRETACIÓN DE HEIDEGgER}

\section{El cógito cartesiano}

Según Heidegger, el cogito está relacionado con la percepción, es un colocar algo delante de sí -tranformando al ente en objeto del que puede disponer. El cogitare -pensar- es percipere: tomar en posesión algo, y hacerlo visible. El cogitare examina y recuenta, es para Heidegger, una "disposición calculante", un poner en seguro. Pero en el mismo acto, el "ego cogito es cogito me cogita$r e^{\prime 14}$, pues no sólo represento algo exterior a mí, el representar objetivo, sino que "estoy remitido a mí". ${ }^{15}$ Esto implica la asunción de una autoconciencia, pues al ser el hombre subjectum, sí mismo, se establece como punto de remisión y de reunión de lo representado que comparece ante él.

El "yo soy, yo existo" en la interpretación de Heidegger se transforma en un "represento, luego soy"16, haciendo depender la constatación y certeza de la existencia ya no del pensar -la actividad que define al yo como sustancia pen-

\footnotetext{
${ }^{11}$ Octave Hamelin, op. cit, p. 137.

12 La "ratio cognoscendi" apunta a causas por las que sabemos algo, mientras la "ratio essendi" apunta a causas por las que algo existe u ocurre.

${ }^{13}$ Cottingham coincide con Hamelin: Descartes deriva la verdad ontológica de la epistemológica, y aun más, deriva conclusiones de la naturaleza real de la mente de premisas sobre las que puede dudar o no. John Cottingham, Descartes, Santa Fé de Bogotá, Norma, 1998, p. 33. Trad. Ángela Calvo de Saavedra.

${ }^{14}$ Martin Heidegger, Nietzsche II, Barcelona, Destino, 2000, p. 128. Trad. José Luis Vermal.

${ }^{15}$ Ibidem, p. 129.

${ }^{16}$ Ibidem, p. 131.
} 
sante en la soledad que la caracteriza - sino del representar, es decir, a partir de la relación objetiva con el mundo, en una relación de interacción de sustancias. El conocimiento de mí mismo, de que yo soy, dependerá del "yo represento": "soy en cuanto aquel que representa"17. El fundamento y el principio se conforman en este sujeto que se representa. Pero Heidegger avanza aún más: no sólo mi ego obtiene certeza de ser sí mismo a partir de configurarse en el punto de referencia de toda representación, sino que además, este ego se arroga la determinación del ser del ente en cuanto representado.

En la interpretación de Heidegger, la verdad como certeza dependerá de la correlación entre el sujeto que representa y el ser del ente mentado en la representación -correspondencia entre intelecto y cosa representada- mientras que en la de Hamelin, ella dependerá de la implicación entre el acto de pensar y la existencia de un sujeto pensante. Mientras en Heidegger se mienta la esencia tanto del sujeto representante como del ente representado, en Hamelin, sólo la existencia del sujeto en su pensar solitario. Además, cabe destacar que Heidegger presupone en su interpretación la existencia de un mundo exterior que pueda ser representable, algo que Descartes deberá avalar después recurriendo a la garantía divina.

Heidegger plantea no sólo una consciencia como punto de referencia y reunión de lo representado, sino una autoconciencia, "un sujeto en el sujeto"18: la expresión "sum res cogitans" implica no solo el representar lo exterior al sujeto, sino el colocarse él mismo en la relación de representación, el "yo", el ser del sujeto que representa, su esencia, es la medida de todo aquello que es representado, ya sean objetos exteriores o el propio sujeto. Puede plantearse pues en Heidegger, un desdoblamiento del "yo": un "yo" trascendental frente a un yo como objeto representable, tan objetivado y cosificado como la sustancia extensa del mundo que lo rodea ${ }^{19}$.

${ }_{17}$ Ibidem, pp. 134s, suprime al "ergo" de la expresión "cogito ergo sum" pues sostiene que no se trata de una deducción (otra diferencia con Hamelin), sino de una constatación: "cogito sum". Esta expresión "no dice ni sólo que yo pienso, no sólo que yo soy, ni que del hecho de mi pensar se sigue mi existencia [...] Dice que soy en cuanto aquel que representa, que no sólo mi ser está determinado esencialmente por este representar, sino que mi representar, en cuanto re-praesentatio determinante, decide sobre la praesentia (Präsenz) de todo representado, es decir, sobre la presencia (Anwesenheit) de lo en él mentado, es decir sobre el ser de este mismo en cuanto ente".

${ }^{18}$ Ibidem, p. 135.

19 Cfr. Amy Morgan Schmitter, "Representation, Self-Representation and the Passions in Descartes", en Review of Metaphysics 48 (1994), pp. 331-357. Frente a esta posición, Schmitter ha argumentado que la posición del sujeto permanece como un punto ciego: ella misma no es representada. El problema que surge de las Meditaciones es la falta de una exposición de la percepción de la posición del sujeto, una que la separe de la percepción del objeto representado sin caer en una inferencia. Para esta 


\section{La "subjetividad" en Nietzsche}

Para Heidegger, Nietzsche modifica la concepción de verdad como valor, que radica en la utilidad para la vida ${ }^{20}$. Sin embargo, el aparente repudio del cogito presente en la voluntad de poder no sería sino un vínculo aún más estrecho con la subjetividad cartesiana. Para este autor, Nietzsche coincide con Descartes en la consideración de que las categorías surgen del pensar, coincide pues en aquello en lo cual cree distanciarse, y se distancia sólo en el modo en que esto ocurre: no se trataría de una certeza inmediata, sino de la operación de una voluntad de poder calculadora y creadora de valores. Nietzsche, pues, aceptaría la noción de sujeto de Descartes, pero relativizaría la verdad tolerándola como un "error necesario", pues la representación fija en una apariencia de detención lo que es deviniente, no lo muestra "como es" ${ }^{21}$. En estas expresiones se presupone la verdad como concordancia del conocimiento que el sujeto tiene con lo real. Esta necesidad del error útil se extiende a la lógica, pues ésta es necesaria como forma de ordenamiento, como "un instrumento de la voluntad de poder". Nietzsche no haría sino continuar con los planteos cartesianos, en la medida en que la misma voluntad de poder es instauradora y calculadora de valores, de igual modo que la yoidad de la conciencia pensante en Descartes. Lo que comparten es la noción de "subjectum" (el yo pensante en Descartes, el cuerpo ${ }^{22}$ en Nietzsche), lo cual traslada el ámbito fundante desde la conciencia a las pulsiones de la voluntad de poder. La caracterización misma de la voluntad de poder le impediría a Nietzsche acceder a la esencia de la metafísica, a su ser. Pues la voluntad de poder es para Nietzsche "la esencia más íntima del ser"$^{\prime 23}$, tiene por lo tanto, carácter metafísico.

autora, Descartes distingue y diferencia claramente el polo-objeto de la posición del sujeto, pues el "yo" no es encubierto por el "me", de esta manera preservando las características y naturaleza de la posición del sujeto. Es en el Tratado de las Pasiones, donde las pasiones denominadas "reflexivas" presentan una conexión entre cuerpo y mente que es representada ante el alma, donde se puede hallar la representación del "yo" en la posición de sujeto. En estas representaciones "de orden superior", no sólo se halla representado el objeto que ocasiona la pasión, sino también el alma, que es el sujeto de las representaciones de las pasiones y además, las conexiones entre sujeto y objeto en la representación. De esta forma se puede representar el "yo" en la posición del sujeto, no en el polo-objeto simpliciter, sino en la posición en la cual la representación se dirige al objeto.

${ }^{20}$ Martin Heidegger, Nietzsche II, p. 151: "lo que pensamos, en cuanto pensado, sólo es 'verdadero' en la medida en que sirve a la conservación de la voluntad de poder".

${ }^{21}$ Ibidem, p. 152.

22 Ibidem, p. 153. Heidegger cita a Nietzsche: "la creencia en el cuerpo es más fundamental que la creencia en el alma".

${ }^{23}$ Ibidem, p. 214. 


\section{Coincidencia entre ambos planteos}

Heidegger enlista, en cuatro puntos, las coincidencias o paralelos entre Descartes y Nietzsche ${ }^{24}$ :

a) el hombre cartesiano es sujeto en el sentido de la "yoidad" representadora, mientras que el hombre para Nietzsche es tal en el sentido de este "fatum último" que es su cuerpo;

b) el ser del ente es la representación para y por el sujeto, mientras que para Nietzsche, el ser es representatividad en la medida en que estatiza con una apariencia lo que es deviniente. Es la voluntad de poder la que constituye el ser (fijo) del devenir;

c) la verdad para Descartes mienta certeza, mientras que para Nietzsche, es un "tener-por-verdadero", que a su vez implica un fijar lo que deviene;

d) para Descartes el hombre es la medida de todo ente en la representación. Para Nietzsche, toda conformación es producto y propiedad del hombre en cuanto que es la voluntad de poder quien instaura las perspectivas desde las cuales se configura el mundo. En efecto, la voluntad de poder calcula sus propias condiciones de incrementación, ella "ordena", "dispone sobre posibilidades" para "autosuperarse": para Heidegger, la voluntad de poder es la esencia del ente en cuanto tal ${ }^{25}$.

La voluntad de poder quiere e instaura valores para asegurarse su intensificación: "la verdad es un valor necesario para la voluntad de poder"26. Lo verdadero implica paradójicamente lo falso en cuanto al ente, pues lo representa en tanto no es, es decir, en tanto fija lo que deviene. La voluntad es esencia de todo lo que es, y por lo tanto, se convierte en "el principio de la posición de valores". La verdad como pensamiento de la voluntad de poder, es un "pensar según valores". Este pensar según valores constituye para Heidegger la "autoconciencia" de la voluntad de poder, como el "contar consigo mismo que ejerce y da poder". De este modo, el pensamiento de valores constituye la identidad de la voluntad de poder, según el modo en el cual ella es subjectum (como fundamento, basada en sí misma). La voluntad de poder se transforma en subjetividad que piensa o calcula en términos de valor $^{27}$.

\footnotetext{
${ }^{24}$ Ibidem, pp. $156 \mathrm{~s}$.

${ }^{25}$ Ibidem, pp. 214s.

${ }^{26}$ Ibidem, p. 254.

${ }^{27}$ Ibidem, pp. 220s.
} 


\section{Presupuestos del planteo heideggeriano}

Como destaca Cragnolini, Heidegger necesita asignar el carácter de consciencia a la voluntad de poder para poder relacionarla con la idea de la subjetividad moderna, en la cual la conciencia tiene la función de "lugar de esclarecimiento", de "espacio" al que se remiten los objetos con la función de hacerlos más claros, comprensibles para una razón que se presume "objetiva". De esta manera, razón y consciencia se alían para dominar todo lo que se les presenta, pues nada puede resistírseles. Nietzsche critica esta presunción de consciencia autónoma, pues ella, por el contrario, no es una zona objetiva, estable, "aséptica" sino que adopta formas provisionales, que surgen de la momentánea configuración de fuerzas, eternamente cambiantes, en las que se plasma el mundo. La conciencia ya no es aquella que trae a sí, o se representa, los objetos del conocimiento, apropiándose de ellos al fijarlos en categorías, sino que es aqueIla ficción, cuya fuerza inventiva genera las categorías para logicizarlas, es decir, tornarlas comprensibles ${ }^{28}$. Sólo en el sentido de "ficción regulativa" puede entonces hablarse de una conciencia, que en función de la necesidad de seguridad y abreviación, genera formas efímeras, que tienen el carácter de "errores útiles":

en realidad, la lógica (al igual que la geometría y la aritmética) es valiosa sólo por las verdades ficticias, que nosotros hemos creado. La lógica es el intento de comprender al mundo real, según un esquema de ser (Seins-Schema) establecido por nosotros, para tornarlo más correcto, formulable, calculable $[\ldots]^{29}$

La conciencia caracterizada de este modo resulta por lo tanto inadecuada como lugar desde el cual juzga el sujeto moderno ${ }^{30}$. La asignación de una autoconciencia a la voluntad de poder constituiría, pues, otro de los presupuestos

\footnotetext{
${ }^{28}$ Friedrich Nietzsche, Sämtliche Werke. Kritische Sudienausgabe, 15 tomos, von G. Colli / M. Montinari (eds.), Berlin / New York, Walter de Gruyter / DTV, 1980 (en adelante, KSA).

Para esta cita, "Nachgelassene Fragmente" (en adelante, NF, seguido de los años a los que pertenecen los fragmentos): NF 1885-1887, KSA 12, 6 (11), p. 237. "Die erfinderische Kraft, welche Kategorien erdichtet hat, arbeitete im Dienst des Bedürfnisses, nämlich von Sicherheit, von schneller Verständlichkeit auf Grund von Zeichen und Klängen, von Abkürzungsmitteln: -es handelt sich nicht um metaphysische Wahrheiten, bei 'Substanz', 'Subjekt', 'Objekt', 'Sein', 'Werden'. Die Mächtigen sind es, welche die Namen der Dinge zum Gesetz gemacht haben: und unter den Mächtigen sind es die grössten Abstraktions-Künstler, die die Kategorien geschaffen haben".

${ }^{29}$ Friedrich Nietzsche, NF 1885-1887, KSA 12, 9 (97) (67), p. 391.

30 Mónica Cragnolini, Nietzsche. Camino y demora, Buenos Aires, Eudeba, 1998, p. 184. Ver de la misma autora: "La constitución de la subjetividad en Nietzsche: metáforas de la identidad", manuscrito de la ponencia presentada al Encuentro Internacional Nietzsche en Perspectiva, Bogotá, septiembre de 2000 , sin indicación de publicación.
} 
de Heidegger en su análisis de Nietzsche, necesario para situar al pensador en el acabamiento de la metafísica.

La unidad de la voluntad de poder que constituye la esencia del ente que es eterno retorno de lo mismo es otro de los supuestos presentes en Heidegger. La voluntad de poder da consistencia a lo que carece de ella, el devenir ${ }^{31}$. Sin embargo, "la" voluntad de poder no existe para Nietzsche, sino sólo la multiplicidad de voluntades de poder que en su constante lucha por el poder cambian, agregándose y desagregándose, y que sólo en virtud de la lucha simulan su unidad y simplicidad ${ }^{32}$.

\title{
4. CRÍticA DE Nietzsche al COgIto CARTESiANo
}

Para esclarecer la diferencia entre los dos planteos, el de Descartes y el de Nietzsche, se analizará con más detenimiento un parágrafo de los póstumos.

\begin{abstract}
Lo que más fundamentalmente me separa de los metafísicos es esto: no les concedo que sea el "yo" (Ich) el que piensa. Tomo más bien al yo mismo como una construcción del pensar, construcción del mismo rango que "materia", "cosa", "sustancia", "individuo", "finalidad", "número": sólo como ficción reguladora (regulative Fiktion) gracias a la cual se introduce y se imagina una especie de constancia y por tanto de "cognoscibilidad" en un mundo del devenir. La creencia en la gramática, en el sujeto lingüístico, en el objeto, en los verbos, ha mantenido hasta ahora a los metafísicos bajo el yugo: yo enseño que es preciso renunciar a esa creencia. El pensar es el que pone el yo, pero hasta el presente se creía "como el pueblo", que en el "yo pienso" hay algo de inmediatamente conocido, y que este "yo" es la causa del pensar, según cuya analogía nosotros entendemos todas las otras nociones de causalidad. El hecho de que ahora esta ficción sea habitual e indispensable, no prueba en modo alguno que no sea algo imaginado: algo puede ser condición para la vida y sin embargo falso. ${ }^{33}$
\end{abstract}

En primer lugar, Nietzsche parece reconocer en Descartes el supuesto de la identificación del acto del pensar con el sujeto que piensa. En su interpretación, Nietzsche parece deslindar el acto del sustrato, lo cual ya había sido hecho por

${ }^{31}$ Martin Heidegger, Nietzsche II, pp. 230-235. Remito al punto 5.3. del presente capítulo.

32 Friedrich Nietzsche, NF 1887-1889, KSA 13, II (73): "[...] Es giebt keine dauerhaften letzten Einheiten, keine Atome, keine Monaden: auch hier ist 'das Seiende' erst von uns hineingelegt, (aus praktischen, nützlichen, perspektivischen Gründen) [...]: Werth ist wesentlich der Gesichtspunkt für das Zunehmen oder Abnehmen dieser herrschaftlichen Centren ('Vielheiten' jedenfalls, aber die 'Einheit' ist in der Natur des Werdens gar nicht vorhanden [...]". Ver también respecto a la crítica a la interpretación heideggeriana, Wolfgang Müller-Lauter, Nietzsche-Interpretationen, 3. Heidegger und Nietzsche, Berlin, Walter de Gruyter, 2000, especialmente pp. 135-193. Müller-Lauter hace esta misma distinción en p. 155.

${ }^{33}$ Friedrich Nietzsche, NF 1884-1885 KSA 11, 35 (35), p. 526. 
la escolástica al distinguir entre concepto formal (el acto de inteligir) que sí requiere una causa por ser real (el intelecto) y el concepto objetivo (lo que conocemos de la cosa, la cosa existente para la mente), que no requiere causa porque no es un ser real, sino de Razón. A su vez, la escolástica distinguía a ambos de la cosa efectiva, la cosa existente en el mundo, independiente de nuestra percepción.

En segundo lugar, Nietzsche plantea la necesidad del autoengaño y de la falsedad para la vida. El hombre, "genio de la mentira" es un artista que viola la realidad mediante la mentira, la que reviste las formas de la metafísica, la moral, la religión, la ciencia. "Las suposiciones más falsas son justamente las más necesarias", pues la falsedad de un concepto no es una objeción a él. Por el contrario, estas ficciones son necesarias para la creencia y confianza en la vida. Ellas desconocen el carácter falso de la existencia, por el contrario, dan al hombre un sentimiento de poder, de dominio sobre la realidad ${ }^{34}$. Mientras el intelecto que piensa es un "aparato falsificador" pero útil porque construye ficciones necesarias para la vida, las categorías construyen ficciones necesarias al conocimiento. En efecto,

\begin{abstract}
esa necesidad de formar conceptos, especies, formas, fines, leyes -'un mundo de casos idénticos'- no se debe comprender en el sentido de que nosotros fuéramos capaces de fijar un mundo verdadero, sino como la necesidad de preparar un mundo en el cual nuestra existencia sea posibilitada -con ello creamos nosotros un mundo calculable, simplificado, comprensible [...] el mundo nos parece lógico, porque nosotros lo hemos logicizado. ${ }^{35}$

De hecho, la lógica (como la geometría y la aritmética) es válida sólo desde las verdades fingidas que nosotros hemos creado. La lógica es el intento, de comprender al mundo real según un esquema de ser (Seins-Schema) establecido por nosotros, para hacérnoslo más correcto, formulable, calculable. ${ }^{36}$
\end{abstract}

Pero este "pensar" a su vez, no está tematizado en este pasaje de Nietzsche: sus productos son construcciones, pero él a su vez parece ser verdadero, es decir, este acto de pensar parece ser ahora el fundamento incuestionado de estas ficciones, entre las cuales se encuentra el yo.

Nietzsche también critica la certeza e indubidatibilidad del cogito. En la innatez del "yo pienso" hay algo que se conoce y ese algo es el "yo" como causa del pensar, a partir del cual se construye el principio de causalidad. El problema

\footnotetext{
527.

${ }^{34}$ Friedrich Nietzsche, NF 1887-1889, KSA 13, II (415) p. 193 y NF 1884-1885, KSA 11, 35 (37), p.

${ }^{35}$ Friedrich Nietzsche, NF 1885-1887, KSA 12, 9 (144), p. 418.

${ }^{36}$ Friedrich Nietzsche, NF 1885-1887, KSA 12, 9 (97) p. 391.
} 
del origen de las ideas consiste en determinar si el yo, el ser de mi pensamiento, es capaz de ser considerado como causa adecuada del contenido representativo de las ideas que piensa ${ }^{37}$, pues este contenido no puede provenir de la nada. En su crítica a Descartes, Nietzsche expresa que cuando se examina la oración "yo pienso" se tropieza con "aseveraciones osadas", cuya justificación es difícil o casi imposible ${ }^{38}$, ¿cómo se puede estar seguro que no se trate más bien de un "querer" o "sentir"? Evidentemente, el "yo pienso" presupone que se comparen estados anteriores para saber en qué consiste, pero esto no implica "ninguna certeza inmediata". El filósofo debería cuestionarse el concepto "pensamiento", su proveniencia, la creencia en causa y efecto, y qué lo habilita a hablar de un yo, de un yo como causa y finalmente de un yo como causa del pensar.

\section{PRoblemas inherentes al COGito CARTESiano}

En las expresiones de Nietzsche, encuentro tres problemas que atañen al cogito cartesiano:

a) El pensar las causas como existentes.

Descartes parte del supuesto de que toda realidad o perfección que está en una cosa, se encuentra formal o eminentemente, es decir, de un modo igual o superior, en su causa. Por lo tanto, la realidad objetiva de la idea, es decir, su contenido representativo ${ }^{39}$, está contenida formalmente en las cosas materia-

\footnotetext{
37 Paolo Lamanna, Historia de la filosofía, Vol. III: De Descartes a Kant, Buenos Aires, Hachette, 1964, pp. 67-69 (citado en Leiser Madanes, "Claridad y distinción, evidencia e intuición", en Historia de la Filosofía Moderna, Materiales de cátedra 1991, 1997, Buenos Aires, Centro de Estudiantes de Filosofía y Letras / UBA.

${ }^{38}$ Friedrich Nietzsche, Jenseits von Gut und Böse, KSA 5, p. 30: por ejemplo, el "que yo sea el que piensa, que generalmente tenga que ser algo, lo que piensa, que el pensar sea una actividad y efecto por parte de un ser que es pensado como causa, que haya un 'yo', finalmente, que esté ya establecido lo que se califica como pensamiento, -que yo sepa, lo que es el pensar".

${ }^{39}$ René Descartes, "Definición III (Apéndice a la Respuesta a las segundas objeciones: Razones que prueban la existencia de Dios y la distinción que existe entre el espíritu y el cuerpo humano, dispuestas de una manera geométrica)", en René Descartes, Meditaciones metafísicas con objeciones y respuestas, pp. 129s. "Por realidad objetiva de una idea, entiendo el ser o la entidad de la cosa representada por la idea, en cuanto esa entidad está en la idea [...]. Pues todo cuanto concebimos que está en los objetos de las ideas, está también objetivamente, o por representación, en las ideas mismas". Que las ideas tengan realidad objetiva, significa que las cosas existen objetivamente en las ideas que las presentan. Lo real está en la idea, no en cuanto real sino de modo ideal.
} 
les, o eminentemente, en nuestra mente o en la de $\operatorname{Dios}^{40}$. Mediante el principio de causalidad, que establece un lazo de efecto y causa entre la realidad objetiva y la realidad formal ${ }^{41}$, Descartes quiere probar que las ideas de las cosas materiales corresponden a existencias reales, para lo cual demostrará que no son producto de nuestra mente ni de la divina. Aquí se plantea el problema del origen de las ideas: el yo, el ser de mi pensamiento, ¿tiene una realidad formal, es decir, un grado de perfección tal como para ser considerado como una causa adecuada del contenido representativo, la realidad objetiva, de las ideas que piensa? En tal caso, ¿el yo puede ser considerado un ser real, existente?

b) El trasladar la certeza e indubitabilidad del cogito en tanto idea innata al cogito como sustrato de las ideas.

Para Descartes las ideas innatas, las ideas del cogito, de Dios y de cosas corporales, se captan por la sola percepción u operación pura del Entendimiento, es decir, no dependen de nada exterior. Se captan por inspección simple de la mente, es decir, por intuición, que en Descartes tiene el sentido de una aprehensión intelectual. La idea innata es un concepto no dudoso de la mente pura, el contenido no varía; es además cierta, pues satisface las notas de claridad (se manifiesta a una mente atenta) y por último, distinta (está separada de las demás). La idea innata del cogito, del "yo pienso" es absolutamente clara, indubitable al intelecto que la piensa. Descartes puede dudar de la existencia de las cosas, pero no puede dudar de que las piensa, aun bajo la forma de la duda.

Ahora bien, las ideas son aquellos pensamientos que reposan en un sustrato, el ego cogito. El término subjectum designa al soporte, en tanto reposa en sí mismo como soporte de las propiedades, constituidas por los cogitata o ideas/pensamientos. El ego cogito es el subjectum privilegiado, pues en él reposa

40 "Definición IV", en René Descartes, Meditaciones metafísicas con objeciones y respuestas, p. 130; "Axioma IV", en Idem, p. 133 y "Axioma V", en Idem, p. 133.

${ }^{41}$ En Descartes, la idea en general, con su realidad objetiva, en cuanto representa algo, es aquello que es inteligido y que conocemos. Descartes plantea tres tipos de realidades, o existencias: la realidad formal de la idea, que con su realidad objetiva (en tanto representación) es aquello que conocemos, y la realidad formal de la cosa, que se conoce confusamente por inferencia causal. La cosa es un doble detrás de la idea que la representa, la idea es una imagen o retrato de las cosas y conocemos la representación de esa cosa en nuestra mente: aquí se funda la aplicación del principio de causalidad: entre la realidad formal y la realidad objetiva se establece un lazo de causa y efecto. Aquí se invierte el planteo escolástico, por el cual el concepto objetivo, es decir, un aspecto o una determinación inteligible de la cosa para el intelecto, es lo que se conoce de la cosa real por medio del concepto formal. En Descartes, el conocimiento es transposición conceptual de la realidad. 
lo único indubitable según Descartes, que es el pensamiento mismo ${ }^{42}$. La noción de subjectum pasa a identificarse con el yo y éste es el único sustrato que posee su ser en sí; el ser de los pensamientos -las cogitationes- y el ser de las cosas pensadas - los cogitata- tienen su ser en otro, es decir, en el yo, en el ego cogito.

Este "yo" sustrato, que es considerado como ser material existente, según el punto anterior es también, en tanto compuesto alma-cuerpo, sede de las pasiones y de las acciones. Este "yo" hereda, como explicaré más adelante, la certeza del cogito por el aspecto autorreferencial del alma, pues ella es sede de un cierto tipo de pasiones, las emociones, que la alteran en su constitución. Descartes sugiere así la fenomenalidad del mundo interno, pues las emociones -que en principio no remiten a nada exterior- causan en el alma una conmoción similar a la que originan las pasiones que pueden referirse a los objetos exteriores en el compuesto.

Por ende, el sustrato, que tiene su ser-en-sí, adquiere las notas de certeza e indubitabilidad que califican a las ideas innatas -entre las cuales se encuentra la del cogito- y de las emociones, de las cuales es su sustento.

c) Y, por último, la cosificación del yo:

Considerando los apartados anteriores, puede establecerse una segunda conclusión: si la causa de una idea debe buscarse en un ser real, existente en sí, que debe contener en esa realidad efectiva tanta riqueza como contenido representativo tiene la idea, y la causa de la idea del cogito es el ego cogito como sustrato, entonces el ego cogito es un ser real, existente. Descartes, como se ha señalado ${ }^{43}$, no sólo cosifica al pensamiento (el pienso y el serpensante son concebidos al modo de la sustancia) sino también a su soporte, el yo ("soy una cosa que piensa"). La cosificación de todo lo existente se desarrolla en la representación, gracias a la cual las cosas ya no son el fundamento que reposa en sí mismo, como en el sistema medieval, sino que remiten al yo del cual dependen.

\footnotetext{
42 René Descartes, "Segunda Meditación", en Idem, p. 224. "No hay, pues, ninguna duda de que existo si me engaña, y engáñeme cuanto quiera, jamás podrá hacer que yo no sea nada en tanto que piense ser alguna cosa [...] yo soy, yo existo, es necesariamente verdadera siempre que la pronuncio o que la concibo en mi espíritu". El cogito es, pues, una intuición racional.

${ }^{43}$ Ver apartado 2, in supra.
} 


\section{El COMPUESTO ALMA-CUERPO, LA "FENOMENALIDAD DEL MUNDO INTERNO" Y LA CERTEZA DE LAS EMOCIONES}

Como se ha visto, en las Meditaciones Descartes excede el alcance del cogito, pues lo que se prueba es la certeza de las ideas y del ser pensante que las piensa, pero de esto no se sigue la certeza del "yo" como sustrato.

Por el contrario, el Tratado de las pasiones parece permitir la asunción de este "yo" sustrato, que, en tanto es capaz de albergar una tonalidad afectiva particular, "el sentir emociones", se constituye en un "yo" empírico y variable. Dos son los tipos de pasiones que me permiten realizar esta aseveración: los "sentimientos" internos, que son pasiones en el alma del cuerpo propio, y las "pasiones o emociones del alma", no internas, que son pasiones en el alma del alma, producidas por los espíritus corporales ${ }^{44}$.

En cuanto a los primeros, cuando los espíritus corporales ${ }^{45}$ causan pensamientos tristes o alegres, estos "sentimientos" ${ }^{46}$ no se atribuyen a la pasión, sino "a la naturaleza o al humor de aquel en quien se han provocado", esto hace que se pueda hablar de un hombre de naturaleza triste o alegre. En este caso, la variación en los sentimientos es debida a a la naturaleza particular de cada hombre, lo que a su vez implica una noción de singularidad.

Con respecto a los segundos, las pasiones "en sentido propio y particular" serán las que proceden del curso de los espíritus, las emociones del alma. Algunas expresan los diversos pensamientos que le llegan, sin alterar su constitución. Pero hay un tipo de emoción particular, los sentimientos de alegría o tristeza, que no pueden ser falsos -es verdadero que el alma los siente- a diferencia de la percepción de objetos exteriores o del propio cuerpo, donde el engaño

\footnotetext{
${ }^{44}$ Esta clasificación fue tomada de Beatriz von Bilderling, "Acciones, pasiones y emociones del alma", apunte de la cátedra Problemas de la Filosofía Moderna, Buenos Aires, SIM, 1999 .

${ }^{45}$ René Descartes, Las pasiones del alma, Madrid, Tecnos, 1997, trad. de José Antonio Martínez y Pilar Andrade Boué: Los espíritus corporales son "partes de sangre muy sutiles [...] cuerpos muy pequeños que se mueven rápidamente", también comparados en el Tratado del hombre con un "viento o una llama muy sutil", que sirven de medio de transporte. Ver ibidem, art. 10 y nota 19, pp. 71s.

${ }^{46}$ Descartes, "Carta a Elisabeth" (del 6.10.1645), en Obras escogidas, pp. 433s: "Pueden Ilamarse pasiones todos los pensamientos que se suscitan en el alma sin el concurso de la voluntad. Pero este nombre se restringe normalmente a los pensamientos causados por cualquier agitación particular de los espíritus. Porque los que provienen de los objetos exteriores, o bien de las disposiciones interiores del cuerpo, $[. .$.$] , se llaman sentimientos, unos exteriores, otros interiores [...] cuando el curso ordinario de$ los espíritus es tal que excita normalmente pensamientos tristes o alegres, u otros semejantes, no se atribuye a la pasión sino a la naturaleza o al humor de aquél en quien se han provocado [...] Así, que se llamen propiamente pasiones no quedan más que los pensamientos que provienen de alguna agitación especial de los espíritus y cuyos efectos se sienten como en el alma misma".
} 
es posible ${ }^{47}$. Estas pasiones, que por su relación con el cuerpo son confusas y oscuras, reciben el nombre de "sentimientos" o mejor aún "emociones del al$\mathrm{ma}^{\prime 48}$, suponen un cambio profundo en la vida sentimental, provocado por los sentidos, ideas o recuerdos que suele traducirse en distintas formas de expre$\operatorname{sión}^{49}$.

Por ende, en el ámbito del alma individual se produce una conmoción afectiva que supone su modificación, alteración cuya intensidad dependerá de la naturaleza particular del hombre que la sufra. Esta tonalidad afectiva, este "sentir emociones", me remite al mundo de la experiencia. Por otra parte, considero importante destacar que este "yo" sustrato hereda la certeza, que en las Meditaciones estaba reservado al cogito, por el aspecto autorreferencial del alma misma - las emociones no remiten a algo exterior. En este sentido, sin embargo, debe considerarse que la alegría es una de las pasiones del alma producida por el movimiento de los espíritus corporales. Si tanto alma como cuerpo están involucrados, puede concluirse que estas emociones ciertas e indudables correspondientes al compuesto constituyen al sustrato en un "yo" empírico y variable.

En tanto pasiones que le advienen al sujeto sin el concurso de su voluntad, considero que estas emociones se constituyen en representaciones, pues estánen-el-lugar-de aquellos sucesos del mundo de la experiencia que son su origen y que el "yo" enfrenta. Por ende, concluyo que Descartes ha dado las indicaciones necesarias para poder postular la fenomenalidad del mundo interno, el cual posee las notas de certeza e indubitabilidad de las que carecen los fenómenos externos.

En esta problemática resulta de particular interés el análisis de Ricoeur: Nietzsche habría anunciado la fenomenalidad del mundo interior, al cual le ata-

${ }^{47}$ René Descartes, Las pasiones del alma, art. 26: "(El engaño no es posible) en lo tocante a las pasiones, pues le son tan cercanas e íntimas a nuestra alma que es imposible que las sienta sin que sean verdaderamente tal y como las siente [...] Aunque estemos dormidos o soñemos, no podríamos sentirnos tristes, o conmovidos por ninguna otra pasión, si no fuera muy cierto que el alma tiene en sí esa pasión".

${ }^{48}$ Ibidem, art. 28: "Emociones del alma, no sólo porque puede atribuirse este nombre a todos los cambios que ocurren en ella, es decir, a todos los diversos pensamientos que le llegan, sino particularmente porque, de todas las clases de pensamientos que puede tener, no hay otras que la alteren y conmuevan tan fuertemente como lo hacen estas pasiones."

${ }^{49}$ Ibidem, nota 44, de J. M. Estrada: "Es lo que nos corrobora la etimología, pues mientras 'sentimiento' (sentiment), de sentire, designa el estado de ánimo que provoca el experimentar sensaciones producidas por impresiones internas o externas, 'emoción' (émotion), de emovere, se refiere a la alteración efectiva que acompaña o sigue a la experiencia de un suceso feliz o desgraciado, o que supone un cambio profundo en la vida sentimental provocado por las impresiones de los sentidos, ideas o recuerdos que suele traducirse en actitudes, gestos u otras formas de expresión [...]". 
ñe la misma incertidumbre que denota la fenomenalidad del mundo exterior. En efecto, si sólo hay interpretaciones y no hechos, el mundo interno puede ser considerado una ficción, un error útil, de la misma manera que lo es toda fijación de la realidad externa. Como he señalado, considero, a diferencia de la lectura de Ricoeur, que esta fenomenalidad interna ya fue sugerida por Descartes mismo; lo que Nietzsche realiza es abolir la diferencia entre un mundo y otro, con lo cual destruye el fundamento en el cual el cogito se basaba.

En la interpretación de Ricoeur, los argumentos de Nietzsche contra el cogito cartesiano se basan en el "funcionamiento de la ilusión como Verstellung", como desplazamiento y disimulación: el lenguaje del que miente o engaña ya no puede ser opuesto al veraz, pues el lenguaje ya está sometido a substituciones e inversiones. Nietzsche procede según una "reducción tropológica": de la misma manera que la duda de Descartes procede de la supuesta falta de distinción entre el estado de ensueño y el del estar despierto, la de Nietzsche procede de la no distinción entre mentira y verdad. En la tesis de Ricoeur, Nietzsche no invierte el cogito cartesiano sino que destruye la pregunta a la cual el cogito debía dar respuesta ${ }^{50}$.

Yo sostengo (ich halte) -afirma Nietzsche- también la fenomenalidad del mundo interno: todo lo que se nos torna consciente, es total y absolutamente ajustado, simplificado, esquematizado, interpretado -el verdadero proceso de la "percepción interior", la relación causal entre pensamientos, sentimientos, deseos, entre sujeto y objeto, está totalmente oculta para nosotros- y quizás sea una pura invención (Einbildung). Este "aparente mundo interno" es tratado con precisamente las mismas formas y procesos que el mundo "externo". Nosotros jamás nos topamos con "hechos": placer y pena son fenómenos recientemente derivados [...]

La "causalidad" nos evade; asumir la existencia de una relación causal inmediata entre pensamientos, como lo hace la lógica -es el resultado de la observación más burda y torpe. Entre dos pensamientos juegan su juego todo tipo de pasiones: pero los movimientos son demasiado rápidos, por ello no podemos reconocerlos, y les negamos su existencia $[\ldots]$

"Pensar", como lo entienden los epistemólogos, jamás tiene lugar: es una ficción totalmente arbitraria, alcanzada gracias a la selección de un elemento del proceso y a la eliminación de todos los restantes, un ajuste artificial en aras de la comprensión (Verständlichung) $[\ldots]$

El "espíritu", algo, que piensa: a veces aun "el espíritu absoluto, limpio y puro" -esta concepción es una segunda consecuencia derivada de la auto-observación falsa, la cual cree en "el pensar": aquí es imaginado primero un acto, que no ocurre de ninguna manera, "el pensar", y segundo, es imaginado un sujeto-sustrato en el cual cada acto

${ }^{50}$ Cfr. Paul Ricoeur, op. cit., pp. 12-15. 
de este pensar -y nada más- tiene su origen: es decir, tanto la acción, como el agente son fingidos". ${ }^{51}$

Ricoeur destaca que al proclamar la fenomenalidad del mundo interno, Nietzsche la equipara con la del mundo externo, y por tanto extiende al mundo interno la falta de objetividad del externo, pues en el último no hay hechos, sino sólo interpretaciones. Nietzsche así destruye el carácter excepcional del cogito gracias al cual Descartes podía distinguir entre el mundo de los sueños y el del despertar. La fenomenalidad no denota, para Nietzsche, objetividad en el sentido de copia fiel de la realidad, sino "arreglo, simplificación, esquematización, interpretación". Asumir la fenomenalidad del mundo interno implica, en primer lugar, alinear la conexión de la experiencia interna con la causalidad externa, la cual es también una ilusión que esconde el deseo de un orden. En segundo lugar, tal asunción conlleva la postulación de una unidad arbitraria, el "pensar", aparte de la multitud de instintos, y en tercer lugar, ella incluye el imaginar un "sujeto sustrato" en el cual el acto de pensar tenga su origen. Esta es la más peligrosa de las consecuencias, pues incurre en una inversión entre el efecto y su causa, pues lo que se toma como causa, el "yo", es el efecto de su propio efecto (este argumento es válido si se introduce la causalidad en la supuesta certeza inmediata del cogito $)^{52}$. En su ejercicio de "duda hiperbólica", el "yo" no aparece como inherente al cogito, sino como una interpretación del tipo causal. Y aquí se encuentra otro argumento tropológico según el cual colocar una substancia bajo el cogito o una causa detrás de él es "simplemente un hábito gramatical, el colocar un agente detrás de cada acción" ${ }^{\prime 53}$.

Para Nietzsche no hay pues sujeto como sustrato, sino que "el sujeto" se disuelve en multitud de pasiones, heterogéneas y no unificables; el autor parece plantear aquí un sujeto "disgregado" en multitud de átomos o más bien, como se verá más adelante, "formaciones de poder" 54 o "complejos del acaecer $^{\prime \prime 55}$, efímeros, que eternamente fluctúan de acuerdo a las circunstancias. El "sujeto" en tanto tal, no es sino una ficción útil, no algo que actúa.

${ }^{51}$ Friedrich Nietzsche, NF 1887-1889 KSA 13, II (113), pp. 53s.

${ }^{52}$ Como se explicitó en el punto 1.2, el cogito es a primera vista una intuición, por lo tanto cierta e inmediata, que luego se revela como deducción: el razonamiento lleva de la existencia del pensamiento a la existencia del sujeto pensante: la causa de mi idea del cogito es el yo como sustrato.

53 Paul Ricoeur, op. cit, pp. 12-15.

${ }^{54}$ Friedrich Nietzsche, NF 1887-1889, KSA 13, II (73), (331), p. 36.

${ }^{55}$ Friedrich Nietzsche, NF 1885-1887, KSA 12, 9 (91), (65), p. 383. 


\section{INNATISMO DEL PENSAMIENTO/ACCIONES}

Con respecto a las ideas innatas, como se ha visto, éstas no dependen de nada exterior, se captan por inspección simple de la mente, por intuición. Su criterio de certeza y verdad es la claridad y distinción de su concepción. Entre ellas, la idea del cogito, el "yo pienso" se plantea como ser-sustrato de todos los pensamientos. Para Nietzsche, "los pensamientos son acciones" ${ }^{56}$, no hay sustrato, no hay "ser" tras la acción, tras la "acción sobre", tras el devenir. Se trata de un "hábito de la gramática" el suponer que a la actividad del pensar corresponde alguien que realiza la acción. ${ }^{57}$ Los pensamientos, los cogitata, no necesitan de un sustrato, los pensamientos son los actos mismos y el agente es comprendido desde la acción, no al revés. El sujeto es una ficción útil pero los pensamientos no se resuelven en la vida contemplativa del espíritu (otra ficción) sino en su transposición a la realidad como hechos. El sujeto como sustrato, base para la justificación de las acciones libres y de la moralidad, no es sino una ficción, un "resto" dejado por el cuerpo, la cosa ${ }^{58}$.

En este sentido, la manera en que está planteado el proceso deductivo/intuitivo del cogito es similar al método de las ciencias criticado por Heidegger:

El procedimiento, por el cual un campo de cosas (Gegenstandsbezirk) se presenta a la imaginación, tiene el carácter de la clarificación de lo claro, de la explicación (Erklärung). Ella es siempre dual. Justifica un desconocido por lo conocido y valora al mismo tiempo este conocido por aquel desconocido. ${ }^{59}$

En efecto, si se aplica este proceder a Descartes, se verá que si lo conocido es el "yo pienso", éste justifica a su vez lo desconocido (Dios), origen de esta idea innata, y a su vez, Dios es la causa de "mi" pensamiento, por lo cual él es valorado como cierto. En realidad, Descartes incurriría en un círculo vicioso.

${ }^{56}$ Friedrich Nietzsche, NF 1885-1887, KSA 12, 1(16), p. 14.

${ }^{57}$ Friedrich Nietzsche, Jenseits von Gut und Böse, KSA 5, p. 31.

58 Friedrich Nietzsche, NF 1885-1887, KSA 12, 2(158), p. 143. "Psychologische Geschichte des Begriffs 'Subjekt'. Der Leib, das Ding, das vom Auge konstruirte 'Ganze' erweckt die Unterscheidung von einem Thun und einem Thuenden; der Thuende, die Ursache des Thuns immer feiner gefasst, hat zuletzt das 'Subjekt' übrig gelassen".

${ }^{59}$ Martin Heidegger, "Die Zeit des Weltbildes", en Holzwege, Berlin, V. Klostermann, 1994, p. 80 (el subrayado es mío). 
Este círculo es destruido por Nietzsche, ya que el "yo" (el sujeto, el "yo" es solamente una ficción regulativa ${ }^{60}$ ) y Dios, son todas ficciones. Si todo se reduce a una ficción con el propósito de ampliar el conocimiento, la cuestión radica en qué medida ella es ventajosa para la vida, éste será pues, el criterio de su provisoria validez. Nietzsche sostiene que "las suposiciones más erróneas son precisamente las más indispensables para nosotros, que sin admitir la validez de la ficción lógica, [...] el hombre no podría vivir" ${ }^{\prime 61}$. Debe suponerse una fuerza ficticia, simuladora, debemos suponer la herencia y perpetuación de las ficciones y su provisoriedad, ya que estas ficciones se mantendrán sólo mientras demuestren su utilidad para logicizar, hacer entendible, la vida.

\section{EL "YO" COMO OBJETO Y COMO FICCIÓN}

Con respecto a la cosificación, Heidegger afirma que sólo lo que se vuelve objeto, "es", vale como siendo (existente - "Seiende"). Naturaleza e historia se convierten en objeto de la imaginación explicativa. La cosificación de lo existente se desarrolla en una representación, que apunta a que aquello existente se presente de una manera tal que el hombre calculador esté cierto y seguro de lo existente. Así es como en Descartes la verdad se convierte en certeza de la representación. Entender al hombre como sujeto implica, en este autor, que el hombre es aquel ser existente sobre el cual se funda todo lo existente en el modo de su ser y verdad, concluye Heidegger. "El Hombre se convierte en representante de lo existente en el sentido de la objetividad". "El que el mundo se convierte en imagen, es el mismo procedimiento por el cual el hombre dentro de lo existente se convierte en subjectum ${ }^{\prime 62}$.

Por ende, la objetivación del yo constituye al mundo como representación. Para Nietzsche, en cambio, el mundo se constituye como ficción, por lo tanto, carente de verdad y de sustrato. La categoría de sustancia, el "existente", es una simplificación para propósitos prácticos, basada en la "creación artificial de casos idénticos" ${ }^{\prime 63}$. Es simplemente un recurso lingüístico, una ficción necesaria

\footnotetext{
${ }^{60}$ Friedrich Nietzsche, NF 1885, KSA 11, 35 (35), p. 526.

${ }^{61}$ Friedrich Nietzsche, Jenseits von Gut und Böse, KSA 5, pp. $18 \mathrm{~s}$.

62 Martin Heidegger, "Die Zeit des Weltbildes", p. 87.

63 Friedrich Nietzsche, NF 1885-1887, KSA 12, 9 (144), p. 418.
} 
para la actividad del pensar. El mundo como ficción es aún así el "material" con el cual trabaja el pensamiento; lo real en cambio, es el dolor, como expresa en La gaya ciencia:

[...] El arte de la transfiguración es por cierto filosofía. No tenemos la libertad de separar alma y cuerpo, como el pueblo lo hace [posible alusión a Descartes] aún tenemos menos libertad de dividir entre alma y espíritu. Debemos dar luz a nuestros pensamientos de nuestro dolor [...] El dolor es el último liberador del espíritu, el maestro de la gran sospecha. ${ }^{64}$

El dolor permite el acceso al cuerpo como "gran razón", como pluralidad de fuerzas, que se descubre como "Selbst". Este ha sido reprimido por la metafísica tradicional dominada por el Ich, o "pequeña razón", que niega la vida al postular un mundo y una conciencia trascendentes ${ }^{65}$. A la corporalidad se une la noción de perspectiva: "sujeto y objeto", "activo y pasivo", "causa y efecto", "medios y fin", son invariablemente nuevas formas de interpretación. Dice Nietzsche en el prólogo de Humano, demasiado humano:

Se debería aprender a comprender lo perspectívico en cada valoración, el corrimiento, deformación y aparente teleología del Horizonte y todo lo que pertenece a la perspectiva, también la parte de tontería (Dummheit) en relación a los valores opuestos y todos los costos intelectuales por los cuales se piensa cada pro y cada contra. Deberíamos captar la necesaria injusticia [...] como inseparable de la vida, la vida misma condicionada por lo perspectívico y su injusticia ${ }^{66}$.

\section{Subjetividad EN NietzSCHE}

Para este autor, el "yo" es una "construcción del pensar" al igual que el resto de otros "schemata" como materia, cosa, sustancia, etc. En realidad, estas nociones no son más que categorías lógico-gramaticales que permiten la elaboración de un aparato falsificador pero necesario para la construcción de ficciones útiles para la vida. Esta "ficción regulativa" se afirma en el espacio entre dos nociones indisociables de la Modernidad: lo absolutamente necesario y lo verdadero, ya que Nietzsche revela que la verdad no es sino una ilusión que fija el devenir, estatizándolo en categorías que se postulan como necesarias: en efecto, estas ficciones son necesarias para la vida, pero al mismo tiempo, son

\footnotetext{
${ }^{64}$ Friedrich Nietzsche, Die Fröhliche Wissenschaft, "Vorrede zur zweiten Ausgabe", KSA 2, pp. 349s. p. 114

65 Mónica Cragnolini, "Tiempo de la salud, tiempo de la enfermedad", Escritos de Filosofía, (1998),

${ }^{66}$ Friedrich Nietzsche, Menschliches, Allzumenschliches, Vorrede 6-7, KSA 2, pp. 20s.
} 
falsas $^{67}$. Son fabulaciones, relativamente necesarias, para la comunicación, con el propósito de definir, entender y explicar. Es más,

"b) Si se ha comprendido que el "sujeto" no es nada que opera (was wirkt), sino una ficción, se siguen variadas consecuencias:

[...] Hemos imaginado la objetualidad (Dinglichkeit) bajo el modelo del sujeto, y la hemos reinterpretado en el caos de las sensaciones. Si no creemos más en el sujeto operante (wirkende Subjekt), también cae la creencia en las cosas operantes (wirkende Dinge), en efectos recíprocos (Wechse/wirkung), causa y efecto entre aquellos fenómenos, a los cuales llamamos cosas [...]

Cae finalmente también, "la cosa en sí": pues ella es en el fondo la concepción de "un sujeto en sí". Pero nosotros entendimos que el sujeto es fingido. La contradicción "cosa en sí" y "apariencia" es insostenible; con ello cae también el concepto de "apariencia".

c) Si renunciamos al sujeto operante, también debemos renunciar al objeto, sobre el cual se opera un efecto (auf das gewirkt wird). La duración, la igualdad consigo mismo, el ser, no inhieren ni en el sujeto ni en aquello que es llamado objeto: ellos son complejos del acaecer (Complexe des Geschehens), aparentemente duraderos en relación a otros complejos -como por ejemplo, por una diferencia en el tiempo del acaecer (reposo-movimiento, firme-suelto: todas contradicciones, que no existen en sí mismas y con las cuales de hecho solo se expresan diferencias de grado (Gradverschiedenheiten), que en una cierta medida de la óptica con la que se mire, se presentan como contradicciones $[\ldots]^{\prime \prime}{ }^{68}$

Para Nietzsche, los productos del pensar son construcciones de un sujeto ficcional, pero este acto de pensar parece ahora ser verdadero, el fundamento de estas ficciones: "un pensamiento viene, cuando "él" quiere, y no cuando "yo" quiero"; se debería decir: "ello piensa". Lo que en principio podría interpretarse como una mera inversión, se revela como una destrucción de supuestos: aún este "ello" no constituye una certeza inmediata ${ }^{69}$, sino que es "una

${ }^{67}$ Friedrich Nietzsche, NF 1884-1885, 35(35), KSA 11, p. 526. "Was mich am gründlichsten von den Metaphysikern abtrennt, das ist: ich gebe ihnen nicht zu, dass das 'Ich'es ist, was denkt: vilmehr nehme ich das Ich selber als eine Construktion des Denkens, von gleichem Range, wie 'Stoff', 'Ding', 'Substanz', 'Individuum', 'Zweck', 'Zahl': also nur als regulative Fiktion, mit deren Hülfe eine Art Beständigkeit, folglich 'Erkennbarkeit' in eine Welt des Werdens hineingelegt, hineingedichtet wird. Der Glaube an die Grammatik, an das sprachliche Subjekt, Objekt, an die Thätigkeits-Worte hat bisher die Metaphysiker unterjocht: diesen Glauben lehre ich abschwören. Das Denken setzt erst das Ich: aber bisher glaubte man, wie das 'Volk', im 'ich denke' liege irgend etwas von Unmittelbar-Gewissen und dieses 'Ich' sei die gegebene Ursache des Denkens, nach deren Analogie wir alle sonstigen ursächlichen Verhältnisse 'verstünden'. Wie sehr gewohnt und unentbehrlich jetzt jene Fiktion auch sein mag, das beweist nichst gegen ihre Erdichtheit: es kann etwas Lebensbedingung und trotzdem falsch sein".

${ }^{68}$ Friedrich Nietzsche, NF 1885-1887, KSA 12, 9 (91), pp. 383s.

${ }^{69}$ Friedrich Nietzsche, Jenseits von Gut und Böse, KSA5, pp. 29s. "Es giebt immer noch harmlose Selbst-Beobachter, welche glauben, dass es 'unmittelbare Gewissheiten' gebe, zum Beispiel 'ich denke', oder 'ich will' [...] Genug, jenes 'ich denke' setzt voraus, dass ich meinen augenblicklichen Zustand mit anderen Zuständen, die ich an mir kenne, vergleiche, um so festzusetzten, was er ist: wegen dieser Rückbeziehung auf anderweitiges 'Wissen' hat er für mich jedenfalls keine unmittelbare 'Gewissheit' [...] Woher nehme ich den Begriff Denken? Warum glaube ich an Ursache und Wirkung? Was giebt mir das Recht, von einem Ich, und gar von einem Ich als Ursache, und endlich von einem Ich als GedankenUrsache zu reden? 
interpretación del proceso y no forma parte del mismo" ${ }^{\prime 70}$. El pensamiento ya no es considerado como uno de los atributos "que me pertenecen: únicamente él no puede ser separado de mím ${ }^{\prime 71}$, como afirma Descartes, sino que se torna independiente de mi voluntad, es decir, ajeno a mi ser: el pensamiento es, pues, uno de los componentes de la exterioridad que me atraviesa, del cruce de fuerzas que inciden en mi cuerpo.

En Nietzsche, el sí mismo se constituye como Selbst, como cuerpo, que Nietzsche opone al yo o alma (Ich). El cuerpo, por lo tanto, se constituye en el "sujeto", "el saber de la corporalidad es el sí mismo, es decir, el cuerpo como construcción de la voluntad de poder (Herrschaftsgebilde). Aquel sujeto aséptico del cartesianismo [...] está ahora atravesado por dolores, enfermedades, placeres." El dolor permite el acceso a lo que ha sido ocultado por el peso de la metafísica: el cuerpo como "gran razón", como pluralidad de fuerzas ${ }^{72}$, como agregaciones y desagregaciones de la voluntad de poder. Cragnolini propone entonces el entender la subjetividad en Nietzsche desde su constitución como "Zwischen", como entrecruzamiento de fuerzas: en este "entre" se cruza todo aquello que fue calificado como "exterioridad" por la subjetividad moderna; el afuera, las circunstancias, los "otros", la historia, el cuerpo. En él, desaparece el binarismo sujeto-objeto, la subjetividad se configura desde la pluralidad. ${ }^{73}$ Este "entre" es también abordado desde la deconstrucción de las nociones modernas de libertad, autonomía y propiedad: la idea de ultrahombre como donación de sí (Loslösung), una "desapropiación de sí" desde el momento en que se acepta que no hay dominio sobre las propias fuerzas, sino fuerzas en constante transformación ${ }^{74}$. La idea de máscara, como "ocultamiento-mostración" permite comprender esta negación de un núcleo identitario: no hay nada por detrás de ella, sino que la identidad se configura en los pliegues, en la superficie, de la(s)

\footnotetext{
${ }^{70}$ Friedrich Nietzsche, Jenseits von Gut und Böse, KSA 5, pp. 30s: "[...] Ein Gedanke kommt, wenn 'er' will, und nicht wenn 'ich' will; so dass es eine Fälschung des Thatbestandes ist, zu sagen: das Subjekt 'ich' ist die Bedingung des Prädikats 'denke'. Es denkt: aber dass dies 'es' gerade jenes alte berühmte 'Ich' sei, ist, milde geredet, nur eine Annahme, eine Behauptung, vor Allem keine 'unmittelbare Gewissheit' [...] Zuletzt ist schon mit diesem 'es denkt' zu viel gethan: schon dies 'es' enthält eine Auslegung des Vorgangs und gehört nicht zum Vorgange selbst".

${ }_{71}^{71}$ René Descartes, Meditaciones metafísicas, Segunda Meditación, p. 226.

72 Mónica Cragnolini, "Tiempo de la salud, tiempo de la enfermedad", pp. 113s. En este escrito, la autora analiza las relaciones entre tiempo, enfermedad, destino e identidad, trazando un paralelo entre La montaña mágica de Thomas Mann y el rol de la enfermedad en Nietzsche.

${ }_{73}$ Mónica Cragnolini, "Filosofía nietzscheana de la tensión: la re-sistencia del pensar", Contrastes. Revista internacional de filosofía, 5 (2000), p. 236. En este texto la autora analiza la idea del "yo en tensión" en el concepto de Zwischen o entre, la interpretación de la voluntad de poder como "razón imaginativa" y la interpretación del instante en el pensamiento del eterno retorno.

${ }_{74}$ Mónica Cragnolini, "La constitución de la subjetividad en Nietzsche: metáforas de la identidad".
} 
máscara(s) ${ }^{75}$. Pero no sólo de "exterioridad" en el sentido moderno está compuesto este cruce de fuerzas, sino de una exterioridad "ampliada": los propios pensamientos, deseos, voliciones y sentimientos, que en Descartes son parte de la propia naturaleza de la res $\operatorname{cogitans}^{76}$, forman parte de este cruce. El cuerpo como Selbst, como exterioridad, es entonces, atravesado por esta multitud de fuerzas también exteriores, las que han "vaciado" la interioridad moderna: es por ello que detrás de la máscara, de la superficie, de los pliegues de la piel, ya no resta nada.

Por ende, el "sujeto" como "Ich" es una ficción producida por el pensamiento, que lejos de conformarse en fundamento, es sólo una interpretación del proceso por el cual se comparan estados actuales con pasados para poder llegar a la conclusión del "yo pienso". En su crítica a la autoconciencia, Nietzsche avanza aún más: este ego no es sino un "fantasma"77, una construcción social con raíces lingüísticas (la obligación de mentir según un sistema de metáforas aceptadas) y disciplinares (la comunicación de nuestras necesidades hace que debamos conocer aunque de modo superficial, a los otros) ${ }^{78}$. La autoconciencia es, en realidad, una imagen de nosotros mismos que nos devuelven los otros, nuestro "egoísmo" es entonces aparente, pues lo que creemos hacer por nuestro yo es hecho por un fantasma creado por otros, razón por la cual todos los sujetos viven en un medio de opiniones impersonales y valores arbitrarios ${ }^{79}$, donde el error es necesario como necesidad de enmascaramiento en aras de la supervivencia ${ }^{80}$, en un mundo también devenido ficción lógica ${ }^{81}$, una "aparien-

75 Cfr. Mónica Cragnolini, "La constitución de la 'identidad' en el pensamiento nietzscheano: sí mismo y máscara. El 'caso Nietzsche' en los inicios del psicoanálisis", Revista de la Facultad de Filosofía, Ciencias de la Educación y Humanidades, vol. 4, 5 (1999).

${ }^{76}$ René Descartes, Meditaciones metafísicas, p. 227: "Pero, ¿qué soy pues? Una cosa que piensa. ¿Qué es una cosa que piensa? Es una cosa que duda, que concibe, que afirma, que niega, que quiere, que no quiere, que también imagina y siente. Por cierto no es poco si todas estas cosas pertenecen a mi naturaleza".

77 Friedrich Nietzsche, Morgenröthe, KSA 3, pp. 92s. "Der Schein Egoismus [...] Die Allermeisten [...] thun trotzdem ihr Lebenlang Nichts für ihr ego, sondern für das Phantom von ego, welches sich in den Köpfen ihrer Umgebung über sie gebildet und sich ihnen mitgetheilt hat, -in Folge dessen leben sie Alle zusammen in einem Nebel von unpersönlichen, halbpersönlichen Meinungen und willkürlichen, gleichsam dichterischen Werthschätzungen [...] alle diese sich selber unbekannten Menschen glauben an das blutlose Abstractum 'Mensch', das heisst, an eine Fiction".

${ }^{78}$ Gianni Vattimo, Etica de la Interpretación, Barcelona, Paidós, 1991, p. 125. Trad. Teresa Oñate,

79 Tema retomado por Heidegger en Sein und Zeit, en su concepción de la caída del Dasein en la cotidianeidad o en lo Uno.

80 Friedrich Nietzsche, Die Fröhliche Wissenschaft, KSA 3, af. 361: "Vom Probleme des Schauspielers", pp. 608s.

${ }^{81}$ Friedrich Nietzsche, Jenseits von Gut und Böse, KSA 5, pp.18s: "Die Falschheit eines Urtheils ist uns noch kein Einwand gegen ein Urtheil; darin klingt unsere neue Sprache vielleicht am fremdesten. Die Frage ist, wie weit es lebensfördernd, lebenserhaltend ist [...] und wir sind grundsätzlich geneigt zu behaupten, dass die falschesten Urtheile (zu denen die synthetischen Urtheile a priori gehören) uns die 
cia", sin la cual el hombre no podría vivir. El aforismo 54 de La gaya ciencia indica la crisis de la subjetividad ${ }^{82}$ y la destrucción de los supuestos del cogito cartesiano: la superficialidad de la conciencia no abre a ningún otro fundamento último, sino a la necesidad de replantearse el rol de la verdad y del ser en una vida que por necesidad de logicización debe crear fundamentos y sentidos provisorios. Se debe continuar soñando sabiendo que se sueña, para así no sucumbir, la mentira es necesaria, sólo así puede mantenerse el sueño de aquellos que reconocen que todo lo vivo no es sino apariencia, locura y danza de espíritus $^{83}$.

\section{EL MUNDO INFORMULABLE DE LAS SENSACIONES}

De esta manera participan todos los atributos tanto del sujeto pensante como del empírico junto con las influencias externas del mundo en este juego de fuerzas que conforman el mundo en Nietzsche. Lo opuesto al mundo fenoménico, caracterizado por el retorno de las cosas conocidas y familiares no es "aquel mundo verdadero" sino el "mundo informe e informulable del caos de las sensaciones -0 sea, otro modo del mundo fenoménico" ${ }^{14}$. Aquí, este mundo "informe" se resiste a ser expresado, en él, el lenguaje encuentra su límite, se muestra impotente, no es capaz de interpretación. Lo caótico es el límite de toda interpretación porque se resiste al conocimiento. Mundo fenoménico y caos conforman empero una totalidad, un mundo que no es orgánico, ni sintetizable, ni unidad simple, y está conformado por el horizonte de todas las formaciones que son tanto caos y necesidad. "No hay nada más que el todo", no hay

unentbehrlichsten sind, dass ohne ein Geltenlassen der logischen Fitkionen [....] der Mensch nicht leben könnte $[\ldots]^{\prime \prime}$.

82 Se puede ampliar este tema en Gianni Vattimo, Etica de la Interpretación, capítulo "La Crisis de la Subjetividad de Nietzsche a Heidegger", pp. 115-142.

${ }^{83}$ Friedrich Nietzsche, Die Fröhliche Wissenschaft, KSA 3, 54, p. 417: "[...] Ich bin plötzlich mitten in diesem Traume erwacht, aber nur zum Bewusstsein, dass ich eben träume und dass ich weiterträumen muss, um nicht zu Grunde zu gehen: wie der Nachtwandler weiterträumen muss, um nicht hinabzustürzen. Was ist mir jetzt ' Schein'! Wahrlich nicht der Gegensatz irgend eines Wesens [...] nicht eine todte Maske [...] Schein ist für mich das Wirkende und Lebende selber, das soweit in einer Selbstverspottung geht, mich fühlen zu lassen, dass hier Schein und Irrlicht und Geistertanz und nichts Mehr ist - dass unter allen diesen Träumenden auch ich, der 'Erkennende' meinen Tanz tanze, dass das Erkennende ein Mittel ist, den irdischen Tanz in die Länge zu ziehen und insofern zu den Festordnern des Daseins gehört [...] (um) eben damit die Dauer des Traumes aufrecht zu erhalten".

${ }^{84}$ Friedrich Nietzsche, NF 1885-1887, 9 (106), KSA 12, p. 395. "[...] Die 'Realität' liegt in dem beständigen Wiederkommen gleicher bekannter, verwandter Dinge, in ihrem logisirten Charakter [....] der Gegensatz dieser Phänomenal-Welt ist nicht 'die wahre Welt', sondern die formlos-unformulirbare Welt des Sensationen-Chaos - also eine andere Art Phänomenal-Welt". 
nada trascendente, nuestro "ser" pertenece al todo, está en el todo, pero no hay nada que pueda medir, comparar nuestro $\operatorname{ser}^{85}$ pues esto sería medir, comparar el todo, colocarse en una posición trascendente al mismo. "Nosotros mismos somos, en contraposición al 'todo' sin unidad del mundo, una totalidad en el mundo" ${ }^{\prime \prime 6}$. Pero esta unidad es una unidad altamente inestable y temporal de innumerables seres en lucha, no se trata aquí de una unidad simple, sino una unidad como ficción de los muchos que se encuentran en relación de lucha por el poder. Esto sin embargo, no anula la función de totalidad, pues al afirmarse a sí mismo, el hombre al mismo tiempo afirma la organización en la cual se halla inscripto ${ }^{87}$.

En la medida en que "conocimiento y devenir se excluyen"88, el caos es para nosotros informulable y por tanto, impensable ${ }^{89}$. La totalidad del mundo se convierte en algo inabordable, indecidible y plantea por lo tanto, un "límite" del pensamiento metafísico moderno, que sólo puede ser aprehendido gracias al engaño de la voluntad a sí misma ${ }^{90}$, gracias a la cual ésta "cree" conocer. Este "límite de lo expresable" propio de la metafísica no consiste en un retorno a la vida instintiva en oposición a la vida de la conciencia, pues "la mayor parte del pensar consciente de un filósofo está guiada de modo secreto por sus instin$\operatorname{tos}^{\prime \prime 1}{ }^{1}$, sino en considerar las valoraciones como ficciones regulativas útiles para la vida, es decir, admitir su no-verdad. Es desde este habla del límite de lo expresable que el caos puede ser asumido como ficción, como forma de mante-

${ }^{85}$ Friedrich Nietzsche, Götzen-Dämmerung, KSA 6, pp. 96s: "[...] Es giebt Nichts, was unser Sein richten, messen, vergleichen, verurtheilen könnte, denn das hiesse das Ganze richten, messen, vergleichen, verurtheilen [...] Aber es giebt Nichts ausser dem Ganzen! - [...] dass die Welt weder als Sensorium, noch als 'Geist' eine Einheit ist, dies erst ist die grosse Befreiung - damit erst ist die Unschuld des Werdens wieder hergestellt [...]".

${ }^{86}$ Wolfgang Müller-Lauter, Über Freiheit und Chaos, Nietzsche-Interpretationen II, Berlin, Walter de Gruyter, 1999, p. 144.

${ }^{87}$ Friedrich Nietzsche, NF 1884-1885, KSA 11, 27 (27), p. 282. "Am Leitfaden des Leibes erkennen wir den Menschen als eine Vielheit belebter Wesen, welche theils mit einander kämpfend, theils einander ein-und untergeordnet, in der Bejahung ihres Einzelwesen unwillkürlich auch das Ganze bejahen".

${ }^{88}$ Friedrich Nietzsche, NF 1885-1887, KSA 12, 9 (89) p. 382.

${ }^{89}$ Ibidem. La concepción de "caos" es tomada de Heráclito: "El mundo es el juego de Zeus" que crea y destruye, que da lugar tanto a un llegar a ser como a la extinción, el juego del fuego consigo mismo, donde "lo uno es en este sentido al mismo tiempo y respecto, lo mucho".

${ }_{90}$ Friedrich Nietzsche, NF 1885-1887, KSA 12, 9 (89) p. 382. "Folglich muss 'Erkenntnis' etwas anderes sein: es muss ein Wille zum Erkennbar-machen vorangehn, eine Art Werden selbst muss die Täuschung des Seienden schaffen."

${ }^{91}$ Friedrich Nietzsche, Jenseits von Gut und Böse, KSA 5, p. 17: "[...] Das meiste bewusste Denken eines Philosophen ist durch seine Instinkte heimlich geführt $[\ldots]^{\prime \prime}$ 
nerse entre la pérdida en el caos absoluto y la ficción como reducción del ser a un nuevo principio ${ }^{92}$.

\section{CONCLUSIÓN}

Para Nietzsche únicamente los sentimientos, sensaciones, emociones e instintos conforman el mundo que podemos reconocer. Sólo los afectos no pueden ser negados, ya que ellos $-y$ no la causalidad-constituyen el elemento de unión de nuestros pensamientos. ${ }^{93} \mathrm{Y}$ a pesar de que Nietzsche niega la verdad del mundo interno de los pensamientos -éste es una ilusión que, al igual que la causalidad, impone al juego de las fuerzas una apariencia de orden ${ }^{94}$ - coincidiría con Descartes en admitir por un lado, que las sensaciones, las emociones y los instintos suscitados por el mundo de la fenomenalidad externa permiten un acceso a este mundo exterior en cuanto sentido y por el otro, que son, además, las únicas percepciones o vivencias que, en cuanto no sólo expresan el mundo de fenómenos internos en una conmoción afectiva -como para Descartes- sino que fundamentalmente guían nuestros pensamientos, no pueden ser puestos en duda en su realidad debido a que nos afectan de forma irremisible.

92 Gianni Vattimo, señala que si la apariencia es tomada como defensa contra el caos de la existencia, ésta es reducida a un único principio, el instinto de conservación, y por lo tanto, es investida de los caracteres de la metafísica del ser (Il soggeto e la maschera. Nietzsche e il problema della liberazione, Milan, Bompiani, $1990^{3}$, p. 29). Por el contrario, Mónica Cragnolini propone que la ficción sea entendida como forma de "mantenerse en el caos", asumiéndolo y tomándolo como "límite del decir" (Nietzsche, camino y demora, p. 172).

${ }_{93}$ Friedrich Nietzsche, NF 1887-1889, KSA 13, II [113] (358), 53f: "Die 'Ursächlichkeit' entschlüpft uns; zwischen Gedanken ein unmittelbares ursächliches Band anzunehmen, wie es die Logik tut - das ist Folge der allergröbsten und plumpsten Beobachtung. Zwischen zwei Gedanken spielen noch alle möglichen Affekte ihr Spiel: aber die Bewegungen sind zu rasch, deshalb verkennen wir sie, leugnen wir sie". $^{\prime \prime}$

${ }^{94}$ Friedrich Nietzsche, NF 1885-1887, KSA 12, 9 [44], 418. 